\title{
Un olvidado viajero y precursor romántico cuzqueño:
}

\section{don José Manuel Valdez y Palacios}

Raúl Porras Barrenechea

\section{Presentación}

1 1 año 1933, Raúl Porras Barrenechea viajó al Brasil como Consejero de la Delegación Peruana a la Conferencia de Río de Janeiro. Permaneció allí hasta el año siguiente, embargado por arduas tareas diplomáticas relacionadas con la solución del diferendo limítrofe con Colombia. No obstante, de esta actividad absorbente, su vocación de historiador encontró tiempo para revisar los fondos de la Biblioteca Nacional de Río, y sus indagaciones se vieron coronadas por el feliz hallazgo de la obra Viagem da cidade do Cuzco a de Belem no Gráo Pará pelos rios Vilcamayu, Ucayaly e Amazonas de José Manuel Valdez y Palacios, viajero cuzqueño y precursor romántico olvidado, que en 1843 se internó por los ríos de la selva en una odisea amazónica que culminó en Río.

Raúl Porras proyectaba la edición del Viagem y con ese propósito obtuvo una reproducción fotográfica del texto de la Biblioteca Nacional de Río, único ejemplar conocido. En 1955, Porras publicó en el suplemento extraordinario de "El Comercio", del 28 de julio, la primera versión de su estudio sobre José Manuel Valdez y Palacios, que luego se reproduciría como parte del libro El paisaje peruano de Garcilaso a Riva Agüero (Lima, 1955). Sería importante para nuestra cultura y para las relaciones de Perú y Brasil cumplir el propósito del maestro Porras de publicar una edición facsimilar de la obra de Valdez y Palacios. 


\section{Un olvidado viajero y precursor romántico cuzqueño: don José Manuel Valdez y Palacios}

$\mathrm{N}^{\mathrm{i}}$ las historias literarias ni las geográficas mencionan el nombre del escritor cuzqueño don José Manuel Valdez y Palacios, viajero intrépido que en 1843 penetró por el Urubamba al Ucayali y al Amazonas, y arribó al Brasil después de una penosa odisea amazónica, de trece meses y más de mil leguas de recorrido entre tribus salvajes, y fue, además, clarísimo portador por su espíritu y su técnica, del virus romántico a la literatura peruana. El inédito José Manuel Valdez lleva el mismo nombre, célebre en nuestros anales científicos y literarios, del famoso médico mulato de la época de Abascal y primeros días de la República, autor de la paráfrasis de los salmos de David que tituló Salterio peruano (Lima, 1833) de quien se han ocupado Lavalle, Riva Agüero y C. E. Paz Soldán. El viajero romántico escribía su apellido, de aristocrática prestancia cuzqueña, con zeta final y usaba el patronímico materno de Palacios. Valdez y Palacios escribió y publicó en Río de Janeiro, en portugués, las impresiones de su viaje en una obra de varias partes que tituló Viagem da cidade do Cuzco a de Belem do Grão Pará pelos rios Vilcamayu, Ucayali e Amazonas, Precedido de hum bosquejo sobre estado politico, moral e litterario do Perú em suas tres grandes épocas; pelo Dr. José Manoel Valdez y Palacios. Río de Janeiro, Typographia Austral, Beco de Bragança 15, 1844. El primer fascículo consta de 244 páginas. El segundo lleva el mismo título general y como subtitulado Quadro comparativo entre o estado actual do Perú e do Brasil; se da como continuación del tomo I, consta de cuatro capítulos y se halla editado en Río de Janeiro, Rua do Sabão N. ${ }^{\circ} 70$, en 1845. El tercer fascículo lleva el título general señalado, consta de 96 páginas y se halla editado en la Typ de M.A. da Silva Lima, Rua de San José N. ${ }^{\circ}$ 8, en el año 1846. En este tercer volumen se halla descrita la primera parte del viaje de Valdez y Palacios, del Cuzco a la región de Santa Ana y Cocabambilla en el Perú. No tengo referencias sobre la publicación posterior de la segunda parte del Viaje, el que sólo alcanza, pues, a la descripción del territorio y paisaje peruano. Leí este curioso folleto en el Brasil en 1934, y, más tarde, obtuve una reproducción fotográfica de él, por el gentil intermedio de Augusto Morelli Pando, culto Secretario de nuestra Embajada en Río.

El nombre del romántico prematura denuncia una calidad social e intelectual de relieve. Los Valdez y Peralta, descendientes de los Valdez y Bazán, fueron en el Cuzco gente de la mayor prosapia, vecinos feudatarios, encomenderos e hidalgos belicosos de romance y desafío, maestres de campo y corregidores, caballeros de Alcántara y de Calatrava, regidores perpetuos del cabildo, y descendientes del factor Don Juan de Salas y Valdez, asturiano, hermano del Arzobispo e Inquisidor de Sevilla D. Hernando de Valdez, linaje prócer cuzqueño al que perteneciera la casona 
solariega de los cuatro bustos en las inmediaciones del Templo del Sol. Pero, al lustre de la sangre hispana, se unía el blasón intelectual de sus dos nombres de castiza prestancia en el Cuzco. A rama ilegítima de tan encopetada familia debió pertenecer el insigne quechuista y dramaturgo, y ejemplar párroco de indios, don Antonio Valdez, autor del Ollantay y, por el lado paterno, Valdez y Palacios debió ser pariente cercano y colaborador del abogado José Palacios, editor del Museo Erudito, del Correo Literario y del Espectador Peruano aparecidos en Lima en 1829. La cercanía espiritual con este último, incansable promotor de cultura en el Cuzco y seguramente uno de los peruanos más ilustrados y conocedor de la literatura europea clásica y romántica, es tan próxima que, casi, llega a confundirse la personalidad no bien esclarecida de ambos. Los Palacios fueron sospechosos de infidelidad al Rey, acaso por su parentesco con Micaela Bastidas, la mujer del Inca Túpac Amaru. José Palacios, que pudo ser el padre del editor del Museo Erudito, fue Escribano de Rentas Reales del Cuzco y fue desterrado a Espańa, bajo partida de registro en 1787.

El abogado José Palacios, editor del Museo Erudito del Cuzco, gala del periodismo de alta cultura nacionalista en el Perú y continuador de la línea del Mercurio Peruano, fue un cultivador feliz de la crítica literaria y profundo conocedor de la literatura antigua y moderna, de las lenguas francesa e inglesa, y quien por su conocimiento de la literatura europea parece haber residido en Europa y absorbido ahí su pericia y refinamiento artístico superior al de nuestros escritores criollos de la época, no sólo en el Cuzco sino en Lima. En su Discurso sobre la literatura en general y la poesía, la epopeya y la tragedia en particular, editado en el Cuzco en 1839, en la imprenta de la Beneficencia, por P. Evaristo González, demuestra su dominio de la filosofía estética y sus vastas lecturas que van desde Virgilio y Horacio a Berceo y Garcilaso, Petrarca y Metastasio, Milton y Shakespeare, Fenelón y Racine, y, particularmente, de la literatura francesa preromántica prendada de la naturaleza y del campo, con el abate Delille, Madame de Stä̈l y, sobre todo, la Nueva Eloisa de Rousseau. Es interesante recoger como expresión del fervor literario de Palacios y de la cultura de un peruano del siglo xix, en las vísperas del romanticismo, estas notas del avezado cuzqueño:

La salida del sol descrita por Tomsom y repetida por Dupaty, las mañanas, las tardes, las noches del paraíso perdido de Milton, el mar cruel de Metastasio, la cascada de Propercio, su Cintia, sus delirios, los jardines de Delille, sus recuerdos a los bordes de la Vanclusa, el lago dorado y el encuentro de las aguas cristalinas de Horacio, las sombras, los árboles de Berceo, la selva umbrosa, el blanco lirio, la rosa colorada de Garcilaso, las lágrimas, los amores, los suspiros de Petrarca, el cuadro en fin de los transportes del amor de Safo son poesías llenas de belleza, de una belleza que agradará en todos los tiempos, que jamás se disminuirá y que será siempre buscada con entusiasmo; por esto nos deleita y hechiza tanto su lectura. 


\section{VIA GEM}

DA CIDA DE

Do

\section{CUZCO A DE BELEM DO GRĪO PARA' \\ PELOS RIOS

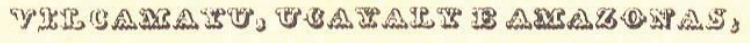 \\ PRECEDIDO DE HUM \\ Bosquejo sobre o estado politico, moral e litterario do Perú em suas tres grandes épocas;}

Pelo Er. Jase Ananoel Daldez y palacios.

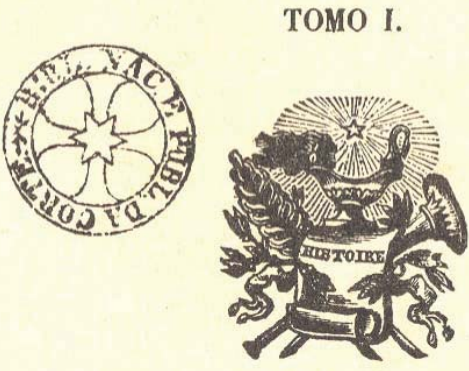

RIO DE JANEIRO,

TYPOGRAPHIA AUSTRAL, BECO DE BRAGANÇA, 15.

1844. 
Esta predilección por la naturaleza, cierto rousseauismo idílico, la preocupación por los temas nacionales y la frecuencia de los mismos autores, aproximan a José Palacios y a José Manuel Valdez y Palacios, a veces hasta las lindes del plagio. Cabe la suposición de que Valdez y Palacios fuera pariente, acaso sobrino, de Palacios y su discípulo y colaborador más ferviente, en su célebre periódico de 1839 .

Del viajero Valdez y Palacios, ausente de todas las bibliografías — con excepción de la Biblioteca Peruana de Paz Soldán que le cita incompletamente- se puede saber, por él mismo, que debió seguir estudios en el Cuzco, pues ostentaba el título de Doctor; que su familia tenía vastas haciendas en el valle de Urubamba; que debió conocer Europa, por las comparaciones que hace entre el valle nativo y las campiñas de Suiza, y que de su estadía en Francia le quedó un amor a los galicismos innecesarios. Valdez y Palacios, según propia confesión, debió ser secuaz intelectual y político de Vivanco durante el Directorio de éste. En el agitado momento de anarquía que siguió a la batalla de Agua Santa, cuando los generales con mando se disputaban la herencia de Gamarra, sin atender al peligro y a la invasión extranjera, debió ganarse Valdez y Palacios la enemistad del general San Román, quien, en sus movimientos basculares entre Torrico y Vidal y entre Castilla y Vivanco, pasó varias veces por el Cuzco, en plan de tropero, allegando fuerzas para sumarse al final a Castilla, después del triunfo de San Antonio. Valdez que trata a San Román de traidor a Vivanco, dice que cometió toda clase de extorsiones en el Cuzco y que, apoyado por «una soldadesca desenfrenada y ávida de sangre» asaltó su casa y la saqueó. Valdez, acosado y en peligro de muerte, huyó al valle del Urubamba donde su familia tenía posesiones; pero hasta ahí, y aun hasta el rincón selvático de la misión de Cocabambilla, le alcanzó el rencor partidista. A pesar del apoyo de los frailes de la misión, Valdez se interna en la región amazónica, con un guía y un hijo pequeño de siete años, corriendo graves riesgos entre los bosques y ríos inmensos y las tribus bárbaras. Es una hazaña civil al mismo tiempo que geográfica. Aparte del Padre Bousquet, misionero que abrió la ruta fluvial del Urubamba al Ucayali en 1806, ningún viajero ni hombre de ciencia había atravesado entonces esas regiones. Castelnau y Marcoy, Markham y Raimondi llegarían años después.

\section{paisajista romántico} $A_{\text {conciencia de su hazańa. «América, escribe orgullosamente al llegar a Río, está todavía }}^{1 \text { salir de Cocabambilla e internarse en la región amazónica, el viajero romántico tiene }}$ virgen, todavía no ha sido vista por los europeos en sus sitios más bellos y misteriosos». La ruta que él va a seguir sólo ha sido hollada por la canoa misionera del Padre Bousquet en 
una parte, y, en otra, desde Huánuco al Pará, por el viajero sajón Lister Maw. El mundo amazónico revelado por las crónicas del siglo Xvi y por el viaje de La Condamine, atrae al neófito peruano del romanticismo porque ha encontrado en él al hombre en estado de naturaleza, «al hombre de la creación», en buena cuenta al bon sauvage de Rousseau y lo ha sorprendido en medio de una "naturaleza inculta» y ha observado sus costumbres, que "en vano se esforzarán en indagar los filósofos en el silencio de sus gabinetes». Él se propone — dice- con mezcla de humildad y de orgullo, relatar únicamente lo que ha visto, seguro de que su narración «arrojará una luz sobre estos países hasta ahora desconocidos». La originalidad y novedad del relato de Valdez y Palacios no está, sin embargo, únicamente en su proeza geográfica, sino en la sensibilidad romántica que el viajero transporta consigo, con anterioridad a la eclosión del romanticismo poético peruano de 1848 definido por Palma y por Riva Agüero e imputado al germen traído por Fernando Velarde. El viajero cuzqueño es un romántico completo, poseído del misticismo de la naturaleza y del amor, de las secretas correspondencias entre el paisaje y el espíritu, amante de la soledad del campo y desdeñoso de las costumbres livianas de la ciudad y de sus engańos, convencido del amargo destino de la humanidad y creyente tan sólo en la fuerza imponderable de la libertad humana. Ha bebido en los clásicos y en los poetas del siglo xviII el amor a la Naturaleza y en Byron, en Schiller y en Goethe su culto de las formas más libres del espíritu. A través de todo su relato se siente encendida la llama romántica inconfundible que colorea sus transportes líricos, bañados muchas veces en lágrimas y sus descripciones campestres inundadas de una suave luz tropical que hace recordar las páginas de la María de Isaacs. Habría que agregar que usa también desembozadamente el término romántico, que llama «románticas» a las campiñas de su tierra por no haber aprendido la «uniformidad poco romántica» de los geométricos parques ingleses, sino que en ellas la naturaleza se abandona a sí misma y prefiere los puentes de junco suspensos sobre el abismo, porque los considera «uno de los espectáculos más románticos». Tristeza, desorden, desaliento y romanticismo puro, aunque no hubieran llegado ni Hugo ni Musset.

El viajero describe en primer término, aunque algo fugazmente, su paso por los Andes y las cordilleras que hay que atravesar del Cuzco a Urubamba y de ésta — hundida en una hoyada tibia y próvida-, al valle de Santa Ana y Cocabambilla. Sus impresiones de los páramos andinos son de un colorido tétrico y desolador, que revelan el espíritu criollo peruano de las ciudades, ya sean ellas costeñas o serranas. En esas «terribles y desoladas regiones», el viajero camina envuelto en sombra y la lluvia no cesa un instante, mientras 
la nieve eterna de las cumbres circundantes semeja entre la niebla vaporosa «como fanales suspensos en los cielos». Las puntas de las cimas desgastadas por el rayo y por los vientos, se le presentan como algo decrépito, ruinoso o terrible, que entristece el corazón y «enleva el alma».

El paisaje de la sierra se le ofrece — como a Garcilaso y Acosta — con sus inmensos y súbitos contrastes. Después de ascender a las cimas nevadas, a la mayor altura a que haya llegado un ser humano «con excepción de Plinio, Humboldt y Ulloa», el viajero tiene que descender casi perpendicularmente a las profundidades de la tierra a un inmenso y cóncavo anfiteatro de diez o doce millas de circunferencia, y de dos mil de profundidad, en el que aparecen los conos de más de sesenta cráteres de volcanes extinguidos, que parecían las «bocas de infierno» de los poetas, «cuadro aflictivo» de grandeza dantesca que descuella en su insólita experiencia, como uno de los fenómenos más sublimes que hubiera presenciado, y duraría en su memoria toda su vida. La sierra bravía de las cumbres y los páramos, ajena al criollo de las ciudades, se le vuelve a presentar en su marcha, después del descanso en el idílico valle del Urubamba, en su marcha desde Ollantaytambo a Cocabambilla. Se extinguen las «campiñas románticas» y las vegas cubiertas de frutillas, los árboles frondosos y la naturaleza se vuelve nuevamente árida, hosca y ascética. La vegetación desaparece y las montañas son para el viajero romántico melancólicas, ora negra, ora pardas, y los oteros distantes unos de otros son «de paja amarillenta, que les da un aspecto sumamente sombrío». El paso por el puerto nevado que conduce a Cocabambilla es, por la psicosis del destierro y del ambiente, triste y desolador, pero de un contraste netamente romántico: «QQué transición tan repentina para la vista y para el corazón —al trasponer una de estas líneas divisorias del paisaje peruano- de un lado la vida, del otro lado la muerte, de un lado el paraíso, de otro lado el infierno!».

El paraíso perdido para el prófugo político estaba a sus espaldas en el valle del Vilcamayo, en las feraces quebradas de Calca, Taray y Urubamba, sobre todo en ésta, su hogar nativo, "verdadero paraíso humano» en primavera, tierra de recreo de los incas, que el viajero se detiene en describir antes de hundirse en la tiniebla amazónica. La nostalgia hogareña detiene y retiene a Valdez y Palacios en el pórtico de su viaje, y dedica casi todas las páginas de la parte publicada de su libro, a describir el paisaje de las hoyadas andinas y las costumbres patriarcales de Urubamba, sus usos vernáculos, sus flores, frutos, fiestas, cantos y cosechas. El paisajista enternecido se vuelve folclorista. El escritor andino Valdez, como el costeño Juan de Arona, enrumba el tema de la naturaleza por una propensión nativista común de su espíritu peruano, hacia el costumbrismo. 
Valdez y Palacios describe embelesadamente el valle del Urubamba o Vilcamayo y sus tierras aledañas, las quebradas de Calca, Taray y Urubamba, con sus aldeas floridas y fragantes de Taray, Pisac, Calca, Urquillos, Urubamba y Ollantaytambo, la vega cubierta de frutillares, perfumada por un océano de arbustos y de verdura matizada de infinitos colores «diluvio de iris» por entre los que pasa el Vilcamayo, como «una cinta verde sinuosamente extendida a manera de una serpiente», en una «atmósfera de azul y oro». Las casas blancas y los techos de tejas asoman entre el oscuro follaje de los melocotoneros y los limoneros y las copas frondosas de los pisonays guarecen con su sombra melodiosa el arrullo de las cuculíes. Todo el valle es un inmenso «jardín salpicado de edificios», en el que «la vegetación es lo principal y la población lo accesorio", sobre todo en Urubamba, rincón edénico con su viejo puente de piedra, su espaciosa iglesia, sus callejas estrechas y sus mansiones rodeadas de jardines aromados, con rosas y camelias, cactus resplandecientes y frescas hortalizas, con fuentes de agua y alamedas y rincones perfumados. Valdez y Palacios evoca y describe la vida de la hacienda andina como Arona había descrito la hacienda costeña. Como en los Cuadros y episodios peruanos de Arona, hay tufillo de cocina criolla y memoria olfativa de guisos domésticos: el chupe humeante, los tamales, el queso fresco, el sabroso asado de vaca o carnero, los capones rollizos y amarillentos, el choclo verde y el ají picante, las humitas, la chicha y el delicioso «italia». El viajero pondera, sobre todo, el ambiente humano, la vida patriarcal de la hacienda y del valle, la sanidad física y moral de sus gentes, la sencillez de las costumbres, la sonrisa que está a flor de labios en mujeres graciosas, hombres robustos y niños fuertes y sanos. Recuerda con emoción los paseos de mozos y doncellas en dulce fraternidad bajo los árboles, las danzas y juegos bucólicos al son del charango o de la guitarra y los yantares sencillos servidos en el césped sobre los vivos colores de las toallas de Cochabamba o de las alfombras de Puno. Enumera y describe los bailes criollos, semejantes a los de la costa: la zamacueca, la mariquita, la mariposa y se estremece de emoción al recordar la melancólica melodía del yaraví. «El yaraví hay que oírlo»: el yaraví «es la música de la naturaleza», «el que no lo ha oído no conoce la voz de la melancolía». El yaraví, dice el viajero romántico con orgullo regional, hace derramar «lágrimas deliciosas» y el que lo escucha se rinde a su melodía. El yaraví es el arma más poderosa del amor en la América española. A través de estos recuerdos, y de las descripciones de los trabajos agrícolas, de las cosechas, se vislumbra la vida dorada de un adolescente de la aristocracia cuzqueña en el plácido vergel de los incas y el recuerdo de unos momentos idílicos de amor casto y juvenil con alguna de esas núbiles doncellas a las que él llama «sacerdotisas del amor rural», recuerdo que vibra en las notas del desterrado como un lamento de yaraví. 
Hay otras notas vivaces en el relato de Valdez. Con emoción poética describe la misión de Cocabambilla, en el umbral de la selva amazónica, el último lugar civilizado del departamento del Cuzco por el este y donde "comienza la montańa» y el país de los antis. En una planicie espaciosa rodeada de cañaverales y de cafetales, iniciados por el franciscano Bousquet, se alza la rústica casa de los misioneros, rodeada de frondosos árboles y arbustos bellísimos y de chacras y jardines donde crecen los naranjos y limoneros, la lujuriosa coliflor ostentando su blanca y fresca cabeza guarnecida de grandes hojas salpicadas de rocío, los sembríos de arroz y de mandioca, la papa y la betarraga dulce, y se yergue como en un romance medioeval la rosa enamorada del ruiseñor. El viajero reposa en Cocabambilla algunos días y parte luego, despidiéndose emocionadamente de los frailes bondadosos a los que recuerda más tarde con lágrimas, viendo perderse los naranjos de la estancia misionera con sus globos de oro, mientras los remos de la canoa rompen el silencio de la selva y se deslizan entre la «vegetación mágica» sobre el «transparente topacio de las aguas».

Entre las escenas e imágenes populares recogidas por Valdez en esta etapa de su viaje, está una que guarda un sabor inmemorial de tiempo prehistórico y que tiene a mi juicio un gran valor etnográfico. Es la estampa de un encuentro o trueque comercial realizado en la selva, lejos de toda influencia occidental, entre los nativos selváticos o antis y los serranos o purunrunas, tal como lo debieron realizar las poblaciones preincaicas. Valdez y Palacios describe la llegada de la flotilla de los antis a la región de Cocabambilla, en medio de un silencio espectacular de los colonos de la misión, que sólo rompen el chasquido de las aguas bajo los remos y los gritos de los papagayos cautivos. Al aproximarse a las riberas de la misión, los antis — cuyo jefe aparece ataviado con sus adornos selváticos — lanzan «un saludo o guriguri agudo que resuena en toda la montaña y va acompañado de mil gesticulaciones extrańas». Los purunrunas responden con gritos y demostraciones de contento. Si es de tarde, se guardan los objetos traídos en las canoas y los antis descienden a dormir. Al día siguiente, al amanecer, los hombres de la selva entonan un himno salvaje a la salida del sol. En las primeras horas alinean sus objetos en hileras en el suelo, custodiados por sus dueños. Los objetos de trueque son papagayos, araras, saccos o vestimentas de salvajes, canoas de cedro, mujeres esclavizadas, cacao silvestre, gomas, resinas, y a cambio de estos productos reciben en trueque cuchillos, machetes, espejos, tijeras, clavos y sal. Ni los antis ni los purunrunas conocen sus respectivos idiomas. «Hácese entonces la permuta por señales, en medio de un profundo silencio». El demandante presenta el objeto que quiere cambiar y señala el que quiere adquirir y la oferta es aceptada o rechazada por signos. La feria dura 
seis u ocho días y la caravana regresa después a su país. Por este sistema sorprendido por el viajero romántico, debieron ingresar al incario y a las civilizaciones del litoral los productos selváticos hallados en las tumbas prehistóricas.

\section{La historia republicana}

$\mathrm{V}$ aldez y Palacios, en su deseo de dar a conocer el Perú en el Brasil, intenta hacer un compendio de nuestra historia republicana, con cierto aliento ideológico y sociológico. Es un empeño que demuestra la audacia intelectual del cuzqueño y su capacidad constructiva en el campo cultural. En 1843, no había aún ningún tratado sistematizado de historia peruana. El bosquejo de Valdez y Palacios, anterior al ensayo de Córdova y Urrutia, Las tres épocas del Perú, también de 1844, tiene así un valor primicial. Valdez y Palacios escribe en Río con datos extraídos del Perú en 1843 y tiene mucha más solvencia intelectual que Córdova y Urrutia. Es, pues, el pionero del paisaje romántico y de la historia republicana. No cabe hacer aquí un examen exhaustivo de su historia política y social del Perú, sino señalar únicamente sus planteamientos y preocupaciones. Está dividido, como el libro de Córdova, por imposición de la materia histórica en tres épocas y precedido de un bosquejo rápido del estado político, moral y literario del Perú en sus tres grandes épocas. Éstas son las siguientes: la anterior a la Independencia, la Independencia, y la República. El planteamiento de Valdez y Palacios incluye el estudio físico del territorio, clima, producciones, y en proyección de historia institucional y económica, no vulgarizada en su época, el análisis de la evolución de la industria, de la agricultura, el comercio y de la religión y literatura.

En la etapa de la Independencia analiza también el estado moral, político y literario y la acción de San Martín y Bolívar en el Perú. La tercera etapa alcanza únicamente a la dictadura de Bolívar, el gobierno de La Mar — a quien considera el Cincinato del Perúy la guerra con Colombia. El segundo fascículo de la Historia comprende un cuadro comparativo entre el estado del Brasil monárquico y el Perú republicano devorado por el caudillismo y la anarquía. De paso, únicamente cabe citar los juicios sobre Gamarra, paisano de Valdez, de quien dice que era «un hábil y profundo hipócrita» y a quien acusa de haber dispuesto del Perú a su antojo y de haberlo repartido entre sus partidarios, "como si fuera un patrimonio suyo». En otra parte, dedicaré mayor espacio a este primer compendio desconocido de historia peruana. 


\section{La leyenda de Ollantay}

Zl nombre de los Valdez y los Palacios está unido al de la leyenda de Ollantay. El cura español, según el Arte nuevo de hacer comedias de Lope de Vega, y vestidura quechua en la clásica lengua cortesana del Cuzco. En el Museo Erudito del Cuzco de 1 de junio de 1837 y en números subsiguientes, publicó don José Palacios, editor del periódico, un estudio de autor anónimo, pero de gran ilustración y solvencia histórica, sobre la «Tradición de la rebelión de Ollantay y acto heroico de fidelidad de Rumiñahui, ambos generales del tiempo de los incas». En dicho artículo, memorable en la historiografía ollantina, se refirió la leyenda de Ollantay, recogiéndola de la versión de un cuzqueño antiguo, quien a su vez la tomaría de las fuentes orales regionales. El editor del Museo dice que la tradición del Ollantay, no recogida por los historiadores, «ha llegado hasta nuestros tiempos por una constante tradición que pocos la ignoran en esta provincia del Cuzco». La única «fuente escrita» sobre esta antiquísima tradición, según el escritor del Museo, fue «la comedia que en lengua quechua formó pocos años ha el doctor don Antonio Valdez, cura de Sicuani». Según el comentarista anónimo, el cura Valdez introdujo en la leyenda de Ollantay «innovaciones y voluntariedades que sin duda se las franqueó la licencia poética». Don Antonio inventó nombres que no figuraban en las leyendas como el de Ima Súmac o Piqui Chaqui, y sobre todo en el desenlace del drama que es de bodas y perdones y en la leyenda se hallaba trunco, «sin expresar el premio ni el castigo».

En 1837, nadie dudaba, de que Antonio Valdez fuera el autor del drama Ollantay. Los contemporáneos lo sabían como una verdad inconclusa, como lo ha demostrado la reciente revelación de un manuscrito del cura Sahuaraura reconociendo la paternidad de su amigo don Antonio Valdez. En los dos años más que duró el Museo Erudito, ningún cuzqueño rectificó esta aserción. Idéntica cosa dijo el cura Justiniani, poseedor del manuscrito del Ollantay, a Markham, quien lo apuntó así la primera vez y lo tradujo después. A partir de Markham y de su ingenuidad sobre leyendas incas, surgió la controversia negando al cura Valdez la paternidad de su gran obra literaria y quechuista, borrándole de los anales de nuestra cultura, en homenaje a un falso indigenismo.

El testimonio de Valdez y Palacios es de sumo interés para el debate de la leyenda ollantina, magistralmente enderezado, después del dislate de Markham y de sus seguidores, por Ricardo Rojas. El autor anónimo del Museo Erudito de 1837 parece ser el mismo Valdez 
y Palacios. En las páginas 50 a 76 de su Viagem, Valdez reproduce como suyo el estudio sobre la leyenda del Ollantay, corrigiéndola, suprimiéndole algunas partes y agregando al final algo que no figuraba en su estudio anterior (el desenlace de Ollantay según las fuentes populares). En su fuga del Cuzco hacia el oriente, Valdez estuvo en Ollantaytambo y pudo recoger, seguramente, ahí o en los poblados del mismo valle, algún eco olvidado de la tradición. Este final que confirma las suposiciones de Rojas en el sentido de que la rigidez incaica no podía haber dado a la rebelión de Ollantay un «final de bodas y perdones» como el del drama de Valdez, viene a ser confirmado por la versión de Valdez y Palacios, que Rojas no conoció.

Dice Valdez y Palacios, y vale la pena reproducirlo, que, después de la captura de Ollantay por Rumiñahui, el Inca juzga al general rebelde y sacrílego, violador del Acllahuasi, y haciendo uso de su clemencia le perdona la vida; "pero como un rebelde no debe existir en mi reino, ordénote que salgas de él con toda su familia y tus bienes para el lugar que quisieres y no vuelvas de él jamás al reino de los incas». La sentencia de Rumiñahui es igualmente ecléctica y expresiva de la prudencia política de los incas:

«Hiciste un servicio a la patria — dice el Inca-, pero traicionaste la amistad y la humanidad. Te concedo, pues, la quinta parte de mis regios rendimientos para ti y tus descendientes y ordénote que con esa fortuna vayas a vivir feliz a otra región. La traición es negra como el Averno y ninguna sombra debe existir sobre el hermoso cielo del imperio de los incas». «Al día siguiente — termina Valdez—, estaban Rumiñahi y Ollantay fuera del territorio peruano». El final, más adecuado que el del drama, exhibe algunos anacronismos como el de las «rentas» del Inca y del Averno y revela alguna recomposición, por lo menos dialéctica, de parte de Valdez y Palacios, pero encierra por lo menos una versión más propia y psicológicamente más veraz que la del engendro dieciochesco, y es el destierro del imperio de los dos generales traidores. La leyenda de Ollantay recobra su equilibrio histórico y moral.

En otra parte de su Viagem consigna Valdez y Palacios algunas noticias sobre el cura Valdez, que confirman palmariamente su capacidad literaria quechuista y su paternidad del Ollantay, si hubiera necesidad de más pruebas. Dice que Valdez fue autor de muchas poesías en quechua, entre ellas de la despedida de Metastasio — publicada en español en el Museo Erudito- que comienza: «Ya llegó el instante fiero, Silvia, de mi despedida», imitada por Arriaza. Dice también, que Valdez prestó a su país el servicio de arrancar del olvido la historia de Ollantay y Rumiñahui, «dando un brillo a la primera aurora de la literatura 
peruana» y que del manuscrito del Ollantay escrito por Valdez «se sacaron algunas copias» y no fue conocido hasta que lo publicó el Museo Erudito. Agrega como dato curioso que don Felipe Pardo, al recibir en Chile la versión del Ollantay del Museo, hizo un poema sobre el asunto de Rumiñahui.

La revelación de la obra de este insigne escritor y humanista cuzqueño tiene gran trascendencia para la historia de nuestra cultura. Revela, en primer término, el notable estado de la ilustración en el Cuzco, al iniciarse nuestra vida independiente, como reflejo de la cultura universitaria colonial. Valdez y Palacios es el continuador de la noble tradición literaria cuzqueña de Garcilaso, del Lunarejo, de Antonio Valdez e Ignacio de Castro, de Sahuaraura y Gallegos, y de los esforzados redactores del Museo Erudito de 1837. Le toca en nuestro panorama cultural abrir las puertas del Dorado amazónico impenetrado y las del romanticismo poético que él inicia con su descubrimiento del paisaje de la sierra y de la selva y con su inconfundible emoción romántica de viajero colorista, nostálgico y apasionado de la libertad. Con él se inicia también la pesadumbre republicana. Ante el espectáculo de la barbarie caudillesca, Valdez y Palacios clama por los ideales frustrados de la Independencia y en una primera explosión del pesimismo, declara con el acento herido de Vigil, de Pardo o de González Prada, «que el Perú no existe» y que es necesario recuperar «su grandeza eclipsada». Su lamento final es típicamente romántico. En una imprecación a sus compatriotas inertes e indolentes, se desliza su concepción romántica y rousseauista de la historia, en la que se exaltan las virtudes del hombre primitivo frente a los vicios del civilizado. Encarándose al Perú de su época, dice: «Tus cobardes habitantes se arrastran hoy desde la cuna a la tumba, esclavos de sátrapas fratricidas, tan sordos a la compasión como orgullosos de sus crímenes, esclavos manchados con todo lo que humilla y hombres con categoría de brutos, careciendo del mérito de una virtud salvaje, sin tener el instinto de la libertad y del valor».

Sin proponérselo, no obstante, su humanismo depurado y su profunda cultura literaria, Valdez y Palacios, romántico improvisado, desemboca en la misantropía de Rousseau y en la falacia romántica del bon sauvage. El Perú republicano podía reeducarse a la manera regresiva del Emilio, aprendiendo ideales de vida en la agreste compañía de los antis amazónicos. 